\title{
Evaluasi Lapang Rekomendasi Pemupukan Padi Sawah Berdasarkan Pemupukan Hara Spesifik Lokasi Berbasis Internet di Jawa Tengah Indonesia
}

\author{
DOI: 10.18196/pt.2017.068.23-33
}

\author{
Samijan*, Tri Reni Prastuti, Warsito \\ Balai Pengkajian Teknologi Pertanian Jawa Tengah, \\ Bukit Tegalepek Sidomulyo Kotak Pos 101 Ungaran Jawa Tengah, Indonesia, Telp. +62 8122935525 \\ *Corresponding author, email: samijan_bptpjtg@yahoo.com
}

\begin{abstract}
ABSTRAK
Pada saat ini petunjuk Pemupukan Hara Spesifik Lokasi (PHSL) pada tanaman padi telah dikembangkan oleh IRRI bersama Badan Penelitian dan Pengembangan Pertanian, melalui media online berbasis website. Untuk memantapkan teknologi rekomendasi tersebut, telah dilakukan pengkajian evaluasi lapang penerapan PHSL online di Desa Trayu dan Dukuh Kec. Banyudono Kab. Boyolali Jawa Tengah pada musim kemarau 2013 (Mei-September 2013 ). Hasil pengkajian di Desa Trayu menunjukkan bahwa sekitar 63,2\% petani, hasil PHSL lebih tinggi dari eksisting (FFP) dengan kisaran sekitar 1-20\%, sedangkan sisanya seimbang sampai lebih rendah dari petani dengan kisaran 1-1 1\%. Hasil pengkajian di Desa Dukuh menunjukkan bahwa sekitar 33,3\% petani, hasil rekomendasi PHSL lebih tinggi dari petani. Sementara sisanya, rekomendasi PHSL seimbang sampai lebih rendah dari hasil petani. Rata-rata pemupukan NPK pada petak PHSL di Desa Trayu lebih rendah dari petani, dengan kisaran dosis pupuk N 133 kh/ha (93,9\% lebih rendah dari petani), Pᄀ205 38 kg/ha (73,8\% lebih rendah dari petani), dan K20 38 kg/ha (14,5\% lebih rendah dari petani). Sementara di Desa Dukuh, dosis pupuk PHSL dengan unsur N 131 kg/ha (109,7\% lebih rendah dari petani), P205 31 kg/ha (29,3\% lebih tinggi dari petani) dan K20 30 kg/ha (63,3\% lebih tinggi dari petani). Secara umum, rekomendasi pemupukan berdasarkan PHSL online memberikan keuntungan sekitar 4,43\% dari eksisting.

Kata kunci: Padi sawah, Pemupukan, Validasi
\end{abstract}

\begin{abstract}
At the recent, guide of Site Specific of Nutrient Management (SSNM) was developed by International Rice Research Isnstitute (IRRI) in collaboration with Indonesia Agency for Agriculture Research and Development (IAARD) through online media based on internet website. To establish this recommendation technology, field evaluation of SSNM online application based on NM-Rice website was conducted. The assessment was conducted in Trayu and Dukuh Village of Banyudono Sub District of Boyolali District of Central Java Indonesia on dry season 2013 (May-September 2013). The assessment result showed that SSNM rice yield of about 63,2\% of farmers in Trayu Village higher than FFP. Yield gap difference of SSNM online varied about 1 -20\% higher than FFP, whereas the others are almost similar until lower than FFP yield, by variation about 1-11\%. The assessment of fertilizer recommendation in Dukuh Village showed that only about 33,3\% of farmers cooperator have SSNM yield higher than FFP. Whereas, the others have SSNM online yield lower than FFP which its involved about 10\% of farmers have similar yield between SSNM and FFP. An average of NPK rate of SSNM online in Trayu Village is lower than FFP. SSNM online rate for $N$ fertilizer recommendation in this location are about $133 \mathrm{~kg} / \mathrm{ha}$ (93,9\% lower than FFP), P205 about $38 \mathrm{~kg} / \mathrm{ha}$ (73,8\% lower than FFP), and K20 about $38 \mathrm{~kg} / \mathrm{ha}$ (14,5\% lower than FFP). Whereas in Dukuh Village, N rate of SSNM online recommendation are about $131 \mathrm{~kg} / \mathrm{ha}$ (109,7\% lower than FFP), P205 about $31 \mathrm{~kg} / \mathrm{ha}$ (29,3\% higher than FFP) and K20 about $30 \mathrm{~kg} / \mathrm{ha}$ (63,3\% higher than FFP). Generally, fertilizer recommendation based on SSNM online have benefit about 4,43\% from existing.

Keywords: Rice fields, Fertilization, Validation
\end{abstract}

\section{PENDAHULUAN}

Pemupukan Hara Spesifik Lokasi (PHSL) merupakan pendekatan pemupukan yang berbasis ilmu pengetahuan dan penelitian untuk memandu penggunaan pupuk secara rasional dan efisien sesuai dengan kebutuhan tanaman (Puslitbangtan, 2006 dan Samijan, 2008). Berdasarkan target penggunaan rekomendasi bagi petani, metode penentuan rekomendasi pemupukan hara spesifik lokasi (PHSL) perlu disederhanakan dengan mempertimbangkan karak- terisitik lahan dan petani secara spesifik lokasi. PHSL adalah panduan berbasis komputer yang dikembangkan oleh International Rice Research Institute (IRRI) bekerjasama dengan Badan Penelitian dan Pengembangan Pertanian melalui Pusat Penelitian atau Balai Penelitian atau Balai Pengkajian Teknologi Pertanian terkait. Panduan tersebut menggunakan jawaban terhadap sejumlah pertanyaan tentang spesifikasi lahan sawah dan praktek pengelolaan oleh petani untuk 
kemudian dihitung dan dihasilkan rekomendasi pemupukan spesifik lokasi lahan sawah yang dapat diperoleh melalui internet (PHSL online) atau telepon genggam (HP). Aplikasi internet PHSL dapat diakses melalui http://webapps.irri.org/ $\mathrm{nm} / \mathrm{id}$ (IRRI, 2011).

PHSL online di Indonesia telah diluncurkan oleh Menteri Pertanian Republik Indonesia pada Januari 2011 (Kementan, 2011). Pada kegiatan kerjasama pengkajian antara IRRI dan Badan Litbang Pertanian, PHSL online telah dikaji oleh Balai Pengkajian Teknologi Pertanian (BPTP) Jawa Tengah dengan melibatkan petugas penyuluh pertanian setempat dan petani. Pengembangan PHSL yang diterapkan terintegrasi dengan pengelolaan lainnya dalam sistem Pengelolaan Tanaman Terpadu (PTT) (Puslitbangtan, 2006). Pengkajian PHSL diperlukan untuk mengevaluasi rekomendasi pemupukan padi sawah di beberapa sentra produksi padi di Indonesia (AGRINA, 2012 dan Puslitbangtan, 2013). Pengkajian evaluasi lapang rekomendasi pemupukan dilakukan melalui uji perbandingan antara PHSL berdasarkan website dengan praktek pemupukan petani secara eksisting. Evaluasi lapang PHSL dilakukan dengan melibatkan petani, petugas penyuluh pertanian dan peneliti untuk mendiskusikan dan mengidentifikasi praktek pengelolaan petani secara eksisting dan merumuskan rekomendasi PHSL.

Menurut Zulkifli (AGRINA, 2012), melalui penerapan PHSL ini petani akan lebih rasional dan tepat waktu dalam menggunakan pupuk untuk padi, sehingga dapat menekan biaya pemupukan. Selain pemupukan menjadi lebih efektif dan efisien, PHSL juga bertujuan meningkatkan produktivitas per satuan luas yang akhirnya dapat berdampak pada peningkatan pendapatan petani. Pengkajian evaluasi lapang PHSL online bertujuan untuk (1) membandingkan dosis pupuk NPK berdasarkan PHSL online dengan dosis pupuk yang biasa dilakukan petani, (2) mengevaluasi keragaan agronomik tanaman dengan penerapan rekomendasi PHSL dibandingkan dengan pemupukan yang biasa digunakan petani, dan (3) mengetahui pengaruh penerapan rekomendasi PHSL online terhadap produktivitas padi dan pendapatan petani dibandingkan pemupukan yang biasa digunakan oleh petani.

\section{BAHAN DAN METODE}

Pengkajian evaluasi PHSL online berdasarkan website dilaksanakan di lahan sawah irigasi di Desa Trayu dan Desa Dukuh Kecamatan Banyudono Kabupaten Boyolali Jawa Tengah, pada musim kemarau (Mei sampai September 2013), melibatkan 40 orang petani kooperator yang tersebar di 2 desa. Lokasi pengkajian merupakan lahan sawah irigasi intensif dengan pola tanam padi sepanjang tahun (padi-padi-padi). Sumber irigasi di Desa Trayu berasal dari bendung sungai, sedangkan di Desa Dukuh berasal dari mata air. Jenis tanah yang berada di lokasi pengkajian didominasi oleh tanah Inseptisol dengan ketinggian tempat sekitar 200 mdpl. Berdasarkan pengalaman petani rata-rata produktivitas padi di desa Trayu lebih rendah dibandingkan Desa Dukuh sekitar 1,0-1,5 t/ha. Rekomendasi pemupukan spesifik lokasi berdasarkan Permentan No. 40/2007, di Kecamatan Banyudono Kabupaten Boyolali adalah Urea $300 \mathrm{~kg} / \mathrm{ha}$, SP36 75 $\mathrm{kg} /$ ha dan KCl 50 kg/ha (Badan Litbang Pertanian, 2007).

Kondisi eksisting petani di Desa Trayu rata-rata memiliki lahan seluas $1.800 \mathrm{~m} 2$ (1/2 pathok) dengan rata-rata varietas padi yang ditanam dari jenis non hibrida yaitu varietas IR64. Namun demikian terdapat sebagian petani yang menanam varietas selain IR64 antara lain varietas Inpari 1, Cimanis, Cimelati dan Memberamo. Umumnya petani di Desa Trayu menanam padi dengan bibit berumur $\geq 21$ hari. 
Rata-rata petani di Desa Trayu belum mengetahui secara pasti kandungan kesuburan tanahnya, namun berdasarkan hasil uji lapang menggunakan alat PUTS oleh petugas diketahui bahwa rata-rata kandungan kesuburan hara $\mathrm{P}$ dan $\mathrm{K}$ di desa ini berada pada status sedang (S), dengan kebiasaan meninggalkan tunggak jerami rata-rata di atas $25 \mathrm{~cm}$. Lahan sawah di desa ini relatif jarang mengalami kekurangan air irigasi, meskipun terkadang harus dilakukan pergiliran. Rata-rata pencapaian hasil padi berkisar 4,00 ton/ha GKG pada musim penghujan dan sekitar 6,36 t/ha GKG pada musim kemarau.

Kondisi eksisting petani di Desa Dukuh rata-rata memiliki lahan seluas $2.000 \mathrm{~m} 2(1 / 2$ pathok) dengan rata-rata varietas padi yang ditanam dari jenis non hibrida yaitu varietas IR64. Selain itu terdapat sebagian petani yang menanam varietas selain IR64 antara lain varietas Inpari 1, Memberamo, Pandanwangi dan Situ Bagendit. Umumnya petani di Desa Dukuh menanam padi dengan bibit berumur $\geq 21$ hari. Oleh karena itu, bagi petani yang menanam padi dari varietas yang umurnya lebih pendek dari IR64 seperti Inpari 1, langkah penting yang perlu dilakukan sebelum menentukan dosis dan waktu pemupukan adalah memastikan untuk menggunakan bibit berumur $\leq 21$ hari. Rata-rata petani di Desa Dukuh juga belum mengetahui secara pasti kandungan kesuburan tanahnya, namun berdasarkan hasil uji lapang menggunakan alat PUTS oleh petugas diketahui bahwa rata-rata kandungan kesuburan hara $\mathrm{P}$ dan $\mathrm{K}$ di desa ini berada pada status sedang (S), dengan kebiasaan meninggalkan tunggak jerami rata-rata di atas $25 \mathrm{~cm}$. Lahan sawah di desa ini relatif jarang mengalami kekurangan air irigasi. Rata-rata pencapaian hasil padi berkisar 5,42 ton/ha GKG pada musim penghujan dan sekitar 7,37 ton/ha GKG pada musim kemarau.
Pengkajian evaluasi lapang PHSL online menggunakan 10 varietas padi yaitu varietas Cimelati, Cimanis, Pandanwangi, IR64, Ciherang, Memberamo, Situ Bagendit, Mekongga, Inpari 1 dan Inpari 8. Luas petakan lahan yang dipergunakan untuk praktek penerapan rekomendasi PHSL berkisar antara 300 sampai 700 meter persegi dari luas pemilikan lahan sekitar 700 sampai 2.700 meter persegi. Panen dilaksanakan mulai 1 Agustus sampai 10 September 2013.

Beberapa tahapan yang dilakukan pada kegiatan evaluasi lapang PHSL online meliputi: (1) Pertemuan diskusi terfokus dengan para calon petani kooperator dan petugas penyuluh pertanian untuk menginventarisir data kondisi eksisting petani, (2) Memproses penghitungan rekomendasi pemupukan menggunakan program PHSL online, (3) Mensosialisasikan rekomendasi pemupukan yang telah dihasilkan berdasarkan perhitungan menggunakan PHSL online untuk dievaluasi bersama, (4) Pelaksanaan di lapangan (tanam, pemupukan, pemeliharaan, pengamatan dan panen).

Aplikasi dosis pemupukan yang dievaluasi pada kegiatan pengkajian ini terdiri dari (1) rekomendasi pemupukan berdasarkan website (PHSL online), dan (2) dosis pemupukan berdasarkan kebiasaan petani (FFP). Luas petakan lahan yang digunakan untuk pengujian PHSL berkisar antara 300-700 $\mathrm{m}^{2}$. Sementara sisa lahan dari total kepemilikan petani dengan petak PHSL digunakan untuk mengkaji dosis pemupukan petani secara eksisting.

Perlakuan dosis pemupukan yang dievaluasi adalah rekomendasi pemupukan yang ditentukan berdasarkan program PHSL online dan pemupukan berdasarkan kebiasaan eksisting petani. Hasil penghitungan dosis pemupukan berdasarkan program PHSL online di Desa Trayu dan Desa Dukuh disajikan pada Tabel 1 dan 2. 
Tabel 1. Rekomendasi Pemupukan Berdasarkan PHSL Online (NM website) di Desa Trayu, Kec. Banyudono, Kab. Boyolali pada tahun 2013

\begin{tabular}{clccccc}
\hline \multirow{2}{*}{ No. } & \multirow{2}{*}{ Varietas } & \multicolumn{2}{c}{ Target Hasil (ton/ha) } & \multicolumn{3}{c}{ Jumlah Pupuk (kg/ha) } \\
\cline { 3 - 7 } & & Minimal & Maksimal & Urea & Phonska & Pelangi \\
\hline 1. & Inpari 1 & 5,50 & 5,89 & - & 211 & 78 \\
2. & Cimanis & 6,11 & 6,50 & 156 & - & 183 \\
3. & IR64 & 6,67 & 7,22 & 178 & - & 194 \\
4. & Inpari 1 & 6,67 & 7,22 & 133 & - & 211 \\
5. & Memberamo & 7,78 & 8,33 & 206 & - & 239 \\
6. & IR64 & 8,33 & 8,89 & 278 & - & 250 \\
7. & IR64 & 8,42 & 8,95 & - & 316 & 121 \\
8. & Memberamo & 9,63 & 9,63 & 260 & - & 297 \\
9. & Cimelati & 7,22 & 7,78 & 278 & - & 217 \\
10. & Memberamo & 6,82 & 7,27 & 168 & - & 200 \\
11. & IR64 & 6,09 & 6,52 & 218 & - & 178 \\
12. & Inpari 1 & 6,11 & 6,50 & - & 233 & 100 \\
13. & Inpari 8 & 8,50 & 9,00 & 250 & - & 260 \\
14. & Inpari 8 & 6,84 & 6,84 & - & 274 & 100 \\
15. & IR64 & 6,67 & 7,22 & 167 & - & 200 \\
16. & IR64 & 7,33 & 7,67 & 189 & - & 222 \\
17. & IR64 & 6,67 & 7,22 & 172 & - & 200 \\
18. & IR64 & 6,84 & 6,84 & 174 & - & 200 \\
19. & IR64 & 6,84 & 6,84 & - & 253 & 105 \\
20. & IR64 & 6,67 & 7,22 & - & 256 & 106 \\
\hline & Rata-rata & 7,09 & 7,48 & 202 & 257 & 183 \\
\hline
\end{tabular}

Sumber: Data primer diolah, 2013

Beberapa data yang diamati dan diinventarisir pada pengkajian ini antara lain komponen agronomis (tinggi tanaman dan jumlah anakan), komponen hasil (panjang malai, jumlah gabah hampa dan isi) dan hasil gabah kering giling per hektar. Data disusun dalam bentuk data tabular spreadsheet dan dianalisa menggunakan uji $\mathrm{T}$ serta secara deskriptif komparatif antara rekomendasi PHSL online dengan yang biasa dilakukan petani. Tingkat efisiensi pemupukan dihitung berdasarkan faktor peubah utama (jumlah dan harga pupuk) dan output (jumlah dan harga jual hasil), serta dilakukan analisis menggunakan model analisis keuntungan sederhana (Simple Benefit Analysis) (IPNI, 2004).
Tabel 2. Rekomendasi Pemupukan Berdasarkan PHSL Online (NM website) di Desa Dukuh, Kec. Banyudono, Kab. Boyolali pada tahun 2013

\begin{tabular}{|c|c|c|c|c|c|c|c|}
\hline \multirow{2}{*}{ No. } & \multirow{2}{*}{ Varietas } & \multicolumn{2}{|c|}{ Target Hasil (ton/ha) } & \multicolumn{4}{|c|}{ Jumlah Pupuk (kg/ha) } \\
\hline & & Minimal & Maksimal & Urea & SP-36 & Phonska & Pelangi \\
\hline 1. & Inpari 1 & 8,33 & 8,89 & 191 & - & - & 141 \\
\hline 2. & Cimanis & 10,56 & 11,11 & 129 & - & - & 417 \\
\hline 3. & IR64 & 10,00 & 10,56 & 136 & - & - & 454 \\
\hline 4. & Inpari 1 & 10,56 & 11,11 & 252 & - & 217 & - \\
\hline 5. & Memberamo & 10,56 & 11,11 & 265 & - & 217 & - \\
\hline 6. & IR64 & 10,00 & 10,00 & 257 & - & 238 & - \\
\hline 7. & IR64 & 9,47 & 9,47 & 306 & - & 247 & - \\
\hline 8. & Memberamo & 10,37 & 11,11 & 214 & - & - & - \\
\hline 9. & Cimelati & 11,67 & 12,22 & 245 & - & 185 & - \\
\hline 10. & Memberamo & 8,18 & 8,41 & 116 & - & - & 284 \\
\hline 11. & IR64 & 8,85 & 9,54 & 187 & 49 & - & - \\
\hline 12. & Inpari 1 & 10,56 & 11,11 & 130 & - & - & 435 \\
\hline 13. & Inpari 8 & 7,35 & 7,50 & 100 & - & - & 257 \\
\hline 14. & Inpari 8 & 9,47 & 9,47 & 138 & - & - & 333 \\
\hline 15. & IR64 & 9,44 & 10,00 & 226 & - & 217 & - \\
\hline 16. & IR64 & 8,95 & 9,47 & 140 & - & - & 320 \\
\hline 17. & IR64 & 8,89 & 9,44 & 123 & - & - & 273 \\
\hline 18. & IR64 & 10,00 & 10,53 & 139 & - & - & 435 \\
\hline 19. & IR64 & 9,47 & 10,00 & 130 & - & - & 313 \\
\hline \multirow[t]{2}{*}{20.} & IR64 & 8,89 & 9,44 & 133 & - & - & 305 \\
\hline & Rata-rata & 9,39 & 9,82 & 178 & 49 & 220 & 331 \\
\hline
\end{tabular}

\section{HASIL DAN PEMBAHASAN}

Perbandingan Penggunaan Pupuk

Rata-rata dosis pupuk rekomendasi PHSL dan pupuk eksisting petani Desa Trayu dan Dukuh disajikan pada Tabel 3. Berdasarkan rekomendasi pemupukan spesifik lokasi yang mengacu pada Permentan No. 40/2007, rekomendasi pupuk di Kecamatan Banyudono Kabupaten Boyolali adalah Urea $300 \mathrm{~kg} / \mathrm{ha}$, SP36 $75 \mathrm{~kg} / \mathrm{ha}$ dan $\mathrm{KCl}$ $50 \mathrm{~kg} / \mathrm{ha}$, atau setara dengan NPK Phonska 200 $\mathrm{kg} / \mathrm{ha}$ dan Urea $235 \mathrm{~kg} / \mathrm{ha}$, atau setara dengan NPK Pelangi $200 \mathrm{~kg} / \mathrm{ha}+$ Urea $215 \mathrm{~kg} / \mathrm{ha}+$ SP36 $20 \mathrm{~kg} / \mathrm{ha}+\mathrm{KCl} 20 \mathrm{~kg} / \mathrm{ha}$ (Badan Litbang Pertanian, 2007). Dengan demikian berdasarkan Tabel 1, rekomendasi PHSL online di Desa Trayu untuk NPK Phonska lebih tinggi (28,5\%), Urea lebih rendah $(-14,0 \%)$ dan Pelangi lebih rendah 
Tabel 3. Perbandingan Takaran Pupuk NPK Pada Rekomendasi PHSL Online Dengan Dosis Pemupukan Eksisting Petani Pada Pengkajian Evaluasi Lapang PHSL Online di Desa Trayu dan Dukuh, Kec. Banyudono, Kab. Boyolali, 2013

\begin{tabular}{|c|c|c|c|c|c|c|c|c|c|c|c|c|c|c|}
\hline \multirow{3}{*}{ No. } & \multicolumn{7}{|c|}{ Desa Trayu } & \multicolumn{7}{|c|}{ Desa Dukuh } \\
\hline & \multirow{2}{*}{ Nama } & \multicolumn{3}{|c|}{ PHSL (kg/ha) } & \multicolumn{3}{|c|}{$\operatorname{FFP}(\mathrm{kg} / \mathrm{ha})$} & \multirow{2}{*}{ Nama } & \multicolumn{3}{|c|}{ PHSL (kg/ha) } & \multicolumn{3}{|c|}{$\operatorname{FFP}(\mathrm{kg} / \mathrm{ha})$} \\
\hline & & $\mathrm{N}$ & $\mathrm{P}_{2} \mathrm{O}_{5}$ & $\mathrm{~K}_{2} \mathrm{O}$ & $\mathrm{N}$ & $\mathrm{P}_{2} \mathrm{O}_{5}$ & $\mathrm{~K}_{2} \mathrm{O}$ & & $\mathrm{N}$ & $\mathrm{P}_{2} \mathrm{O}_{5}$ & $\mathrm{~K}_{2} \mathrm{O}$ & $\mathrm{N}$ & $\mathrm{P}_{2} \mathrm{O}_{5}$ & $\mathrm{~K}_{2} \mathrm{O}$ \\
\hline 1. & P. Pariyanto & 97 & 0 & 0 & 166 & 45 & 45 & Sri Mulyani & 116 & 14 & 14 & 384 & - & - \\
\hline 2. & Suyamto & 119 & 23 & 23 & 264 & 22 & 22 & Mulyono & 143 & 42 & 42 & 380 & 34 & 34 \\
\hline 3. & Gatot & 132 & 27 & 27 & 206 & 34 & 34 & G. Ngadiman & 154 & 45 & 45 & 380 & 34 & 34 \\
\hline 4. & Tarmo Santoyo & 133 & 20 & 20 & 160 & 22 & 22 & Fajar & 149 & 33 & 33 & 228 & 24 & - \\
\hline 5. & Dwijo Suwito & 193 & 74 & 74 & 292 & 82 & 82 & Sutrimo & 155 & 33 & 33 & 313 & - & - \\
\hline 6. & Jarkasi & 216 & 42 & 42 & 384 & - & - & Jumadi & 154 & 36 & 36 & - & - & - \\
\hline 7. & Tasmin & 75 & 0 & 0 & 163 & 30 & 30 & Sahir & 178 & 37 & 37 & 180 & - & - \\
\hline 8. & Cono & 131 & 39 & 39 & 153 & 39 & 39 & Joko Subroto & 119 & 10 & 10 & 224 & 156 & 34 \\
\hline 9. & Rudiman & 124 & 42 & 42 & 278 & 69 & 69 & Widono & 140 & 28 & 28 & 131 & 99 & 38 \\
\hline 10. & Sutardi & 109 & 46 & 46 & 345 & 67 & - & Supomo & 110 & 28 & 28 & 112 & 9 & 9 \\
\hline 11. & Atmo Waluyo & 154 & 33 & 33 & 344 & 34 & 34 & Jumino & 65 & 18 & - & 469 & - & - \\
\hline 12. & Wito Daliyo & 122 & 33 & 33 & 280 & 111 & 111 & Widodo & 147 & 43 & 43 & 224 & 34 & 34 \\
\hline 13. & Darmo & 125 & 38 & 38 & 457 & 112 & 112 & Budiyono & 97 & 26 & 26 & 58 & 14 & 14 \\
\hline 14. & Pardi & 68 & 0 & 0 & 213 & 49 & 49 & Trijoko & 130 & 33 & 33 & 270 & - & - \\
\hline 15. & Wiji & 118 & 25 & 25 & 293 & 162 & - & Rochmad & 137 & 33 & 33 & 313 & - & - \\
\hline 16. & Amir & 144 & 28 & 28 & 286 & 62 & 62 & Slameto & 128 & 32 & 32 & 384 & - & - \\
\hline 17. & Maryono & 127 & 52 & 52 & 200 & 28 & 28 & Suherjan & 111 & 27 & 27 & 90 & 14 & 14 \\
\hline 18. & Saryono & 120 & 50 & 50 & 310 & 216 & - & Slamet M & 151 & 43 & 43 & 469 & - & - \\
\hline 19. & Harno & 191 & 96 & 96 & 166 & 45 & 45 & Supami & 123 & 31 & 31 & 313 & - & - \\
\hline \multirow[t]{2}{*}{20.} & Panut & 168 & 84 & 84 & 208 & 75 & 75 & Suyamto & 122 & 30 & 30 & 313 & - & - \\
\hline & Rata-rata & 133 & 38 & 38 & 258 & 69 & 54 & Rata-rata & 131 & 31 & 32 & 276 & 46 & 26 \\
\hline
\end{tabular}

Sumber : Data primer diolah, 2013

$(-8,5 \%)$ dari rekomendasi Permentan. Sementara rekomendasi PHSL online di Desa Dukuh untuk NPK Phonska sedikit lebih tinggi (10\%), NPK Pelangi lebih tinggi $(65,5 \%)$, dan Urea lebih rendah $(-24,2 \%)$ dari rekomendasi berdasarkan Permentan 40/2007.

Kebiasaan pemupukan petani di Desa Trayu berdasarkan hasil pengamatan dan wawancara dengan petani sebagaimana disajikan pada Tabel 3 terlihat bahwa penggunaan pupuk NPK tergolong tinggi dibandingkan PHSL, yaitu sekitar $258 \mathrm{~kg} / \mathrm{ha} \mathrm{N}, 65 \mathrm{~kg} / \mathrm{ha} \mathrm{P}_{2} \mathrm{O}_{5}$ dan $43 \mathrm{~kg} / \mathrm{ha} \mathrm{K}_{2} \mathrm{O}$. Sementara di Desa Dukuh penggunaan pupuk $\mathrm{N}$ sedikit lebih tinggi namun untuk $\mathrm{P}$ dan $\mathrm{K}$ jauh lebih rendah dari Desa Trayu, yaitu masingmasing sekitar $262 \mathrm{~kg} / \mathrm{ha} \mathrm{N}, 21 \mathrm{~kg} / \mathrm{ha} \mathrm{P}_{2} \mathrm{O}_{5}$ dan $10 \mathrm{~kg} / \mathrm{ha} \mathrm{K}_{2} \mathrm{O}$.
Berdasarkan hasil penelitian PHSL dalam jangka panjang, bahwa untuk setiap kenaikan hasil gabah sebesar 1 ton/ha dibutuhkan pupuk $\mathrm{N}$ sebesar $40 \mathrm{~kg}$ untuk musim panen tinggi dan sekitar 50-60 kg N untuk musim panen rendah, pupuk $\mathrm{P}_{2} \mathrm{O}_{5}$ sekitar $5 \mathrm{~kg} / 1 \mathrm{t} /$ ha hasil. Di sisi lain, kebutuhan pupuk $\mathrm{K}$ sangat ditentukan oleh pengelolaan jerami, air irigasi dan jenis tanahnya (Buresh, 2008). Rekomendasi pemupukan berdasarkan PHSL untuk jenis pupuk $\mathrm{N}$ ratarata lebih rendah dari petani, sedangkan untuk pemupukan P dan K di Desa Dukuh cenderung lebih tinggi dari petani masing-masing sebesar 29,3\% dan 63,3\%.

Berdasarkan rata-rata dosis pemupukan PHSL dan FFP sebagaimana disajikan pada Tabel 3 terlihat bahwa secara umum dosis pemupukan 
NPK yang direkomendasikan PHSL online di Desa Trayu jauh lebih rendah dari pemupukan eksisting petani. Rata-rata dosis pemupukan $\mathrm{N}$ menurut panduan PHSL sekitar $133 \mathrm{~kg} / \mathrm{ha}$ atau 93,8\% lebih rendah dari petani, pupuk $\mathrm{P}_{2} \mathrm{O}_{5} 38 \mathrm{~kg} / \mathrm{ha}$ atau $82,5 \%$ dan pupuk $\mathrm{K}_{2} \mathrm{O} 38$ $\mathrm{kg} / \mathrm{ha} 42,8 \%$ lebih rendah dari petani. Jumlah takaran pupuk $\mathrm{N}$ pada rekomemdasi PHSL online ini diestimasi dari target hasil yang dicapai, oleh karena jumlah unsur $\mathrm{N}$ yang diserap tanaman terkait langsung dengan hasil tanaman. Sementara untuk mempertahankan keberlanjutan hasil padi yang tinggi, kebutuhan hara $\mathrm{P}$ dan $\mathrm{K}$ biasanya tidak bisa dicukupi dari suplai alami, oleh karena itu perlu ditambahkan pupuk dalam jumlah yang tidak terlalu banyak guna menghindari terjadinya defisiensi dalam jangka panjang (Buresh et.al., 2006).

Berdasarkan hasil pengamatan terhadap ratarata pemupukan sebagaimana disajikan pada Tabel 7 terlihat bahwa rata-rata dosis pemupukan menurut acuan PHSL di Desa Dukuh jauh lebih tinggi dari pemupukan petani terutama pupuk $\mathrm{N}$ dan P. Sementara untuk dosis pupuk K menurut acuan PHSL justru lebih tinggi dibandingkan petani. Dosis pemupukan $\mathrm{N}$ menurut acuan PHSL di Desa Dukuh berkisar $131 \mathrm{~kg} / \mathrm{ha}$ atau lebih rendah sekitar 109,6\% dari pemupukan petani, dosis pupuk $\mathrm{P}_{2} \mathrm{O}_{5}$ sekitar $31 \mathrm{~kg} /$ ha atau 49,3\% lebih rendah, dan pupuk $\mathrm{K}_{2} \mathrm{O}$ sekitar 32 $\mathrm{kg} /$ ha atau $17,0 \%$ lebih tinggi dari petani.

Apabila dibandingkan dengan rekomendasi pemupukan spesifik lokasi berdasarkan Permen$\tan$ No. 40/2007 (138 kg N/ha, 27 kg $\mathrm{P}_{2} \mathrm{O}_{5} /$ ha, $30 \mathrm{~kg} \mathrm{K2O} / \mathrm{ha}$ ), secara umum rekomendasi pemupukan berdasarkan PHSL online untuk unsur $\mathrm{N} 4,1 \%$ lebih rendah, $\mathrm{P}_{2} \mathrm{O}_{5} 27,2 \%$ lebih tinggi dan $\mathrm{K}_{2} \mathrm{O} 15,6 \%$ lebih tinggi dari Permentan.

Dengan memperhitungkan selisih takaran unsur hara dalam pupuk antara rekomendasi
PHSL online dengan eksisting petani (Tabel 3), serta tingkat perbedaan hasil gabah yang dicapai (Tabel 5 dan 7), maka dapat diketahui tingkat efisiensi agronomi dari penerapan suatu rekomendasi pupuk. Prinsip dari efeisiensi agronomi adalah berapa kilogram gabah dapat dihasilkan dari setiap kilogram unsur dalam pupuk $(\mathrm{kg} / \mathrm{kg})$. Berdasarkan hasil perhitungan nisbah dari selisih unsur dalam pupuk dengan selisih gabah yang dihasilkan, rata-rata efisiensi agronomi pada rekomendasi PHSL online untuk pupuk $\mathrm{N}$ sebesar 0,7 $\mathrm{kg} / \mathrm{kg}$, P dan $\mathrm{K}$ masing-masing $2,3 \mathrm{~kg} / \mathrm{kg}$.

\section{Pertumbuhan Tanaman dan Hasil Padi}

\section{Desa Trayu}

Berdasarkan keragaan pertumbuhan tanaman padi di Desa Trayu terlihat bahwa perlakuan pemupukan berdasarkan PHSL online tidak berbeda nyata terhadap tinggi tanaman dan jumlah anakan. Rata-rata tinggi tanaman dengan pemupukan PHSL sekitar 65,6 cm dan pemupukan petani sekitar $65,8 \mathrm{~cm}$. Sementara rata-rata jumlah anakan produktif pada petak perlakuan pemupukan PHSL sedikit lebih banyak dari pemupukan petani yaitu masing-masing 26 tanaman dan 24 tanaman. Rata-rata pencapaian tinggi tanaman dan jumlah anakan disajikan pada Tabel 4.

Berdasarkan hasil pengamatan terhadap ratarata panjang malai, jumlah gabah isi dan gabah hampa, keragaan komponen hasil di Desa Trayu untuk perlakuan PHSL dan eksisting petani tidak menunjukkan adanya perbedaan yang nyata. Rata-rata panjang malai pada petak PHSL dan petani masing-masing 23,1 dan 22,9 cm. Sementara rata-rata pencapaian jumlah gabah isi dan gabah hampa untuk perlakuan PHSL adalah 102/30 dan eksisting petani 111/37. Panjang malai dan jumlah gabah isi hampa di Desa Trayu disajikan pada Tabel 5. Hasil evaluasi lapang PHSL online di Desa Trayu sebagaimana disaji- 
kan pada Tabel 5 menunjukkan bahwa rata-rata hasil yang dicapai PHSL online lebih tinggi dari hasil eksisting petani sekitar 11,0\% (dari 63,2\% petani). Sementara sekitar 30,6\% petani kooperator menunjukkan bahwa rata-rata hasil PHSL online lebih rendah dari hasil eksisting petani sekitar $5,8 \%$.

Tabel 4. Rata-Rata Pencapaian Tinggi Tanaman dan Jumlah Anakan Produktif Pada Pengkajian Evaluasi Lapang PHSL Online di Desa Trayu, Kec. Banyudono, Kab. Boyolali pada tahun 2013

\begin{tabular}{|c|c|c|c|c|c|}
\hline \multirow{2}{*}{ No. } & \multirow{2}{*}{ Nama } & \multicolumn{2}{|c|}{ Tinggi Tanaman $(\mathrm{cm})$} & \multicolumn{2}{|c|}{ Jumlah Anakan } \\
\hline & & PHSL & FFP & PHSL & FFP \\
\hline 1. & Parihadi Pariyanto & 52,4 & 50,8 & 20 & 20 \\
\hline 2. & Suyamto & 82,0 & 82,8 & 21 & 21 \\
\hline 3. & Gatot & 59,2 & 62,6 & 28 & 28 \\
\hline 4. & Tarmo Santoyo & 64,6 & 63,8 & 25 & 24 \\
\hline 5. & Dwijo Suwito & 71,0 & 75,6 & 24 & 23 \\
\hline 6. & Jarkasi & 62,6 & 60,8 & 25 & 23 \\
\hline 7. & Tasmin & 56,6 & 63,8 & 22 & 27 \\
\hline 8. & Cono & 80,0 & 77,4 & 22 & 24 \\
\hline 9. & Rudiman & 65,4 & 66,2 & 38 & 24 \\
\hline 10. & Sutardi & 68,0 & 77,0 & 21 & 29 \\
\hline 11. & Atmo Waluyo & 65,0 & 63,8 & 32 & 25 \\
\hline 12. & Wito Daliyo & 60,4 & 57,6 & 29 & 22 \\
\hline 13. & Darmo & 74,0 & 67,0 & 27 & 25 \\
\hline 14. & Pardi & 59,0 & 56,6 & 27 & 30 \\
\hline 15. & Amir & 81,4 & 82,2 & 26 & 22 \\
\hline 16. & Maryono & 58,4 & 57,2 & 28 & 24 \\
\hline 17. & Saryono & 60,2 & 54,8 & 23 & 27 \\
\hline 18. & Harno & 50,6 & 52,2 & 20 & 20 \\
\hline \multirow[t]{5}{*}{19.} & Panut & 70,8 & 73,8 & 27 & 29 \\
\hline & Rata-rata & 65,34 & 65,57 & 24,53 & 24,58 \\
\hline & Standar Deviasi & 9,25 & 9,95 & 3,08 & 3,04 \\
\hline & Significantly Value & \multicolumn{2}{|c|}{0,651} & \multicolumn{2}{|c|}{0,936} \\
\hline & Thitung / T-tabel & \multicolumn{2}{|c|}{$-0,74 / 1,69$} & \multicolumn{2}{|c|}{$-0,53 / 1,69$} \\
\hline
\end{tabular}

Sumber: Data primer diolah, 2013

Berdasarkan hasil uji T data tinggi tanaman dan jumlah anakan memiliki nilai perbedaan (significantly value) $>5 \%$ yang berarti data kedua perlakuan (PHSL dan FFP) relatif homogen. Apabila dilihat dari nilai T-hitung yang lebih kecil dari T-tabel menunjukkan kedua perlakuan memiliki rata-rata hasil yang relatif sama. Nilai negatif pada T-hitung menunjukkan adanya indikasi bahwa perlakuan PHSL memiliki nilai yang relatif lebih rendah dibandingkan FFP.

Tabel 5. Data Panjang Malai, Gabah Isi dan Gabah Hampa, dan Hasil Gabah Pada Evaluasi Lapang PHSL Online di Desa Trayu, Kec. Banyudono, Kab. Boyolali pada tahun 2013

\begin{tabular}{|c|c|c|c|c|c|c|c|c|c|}
\hline \multirow{2}{*}{ No. } & \multirow{2}{*}{ Nama } & \multicolumn{2}{|c|}{$\begin{array}{l}\text { Panjang } \\
\text { Malai (cm) }\end{array}$} & \multicolumn{2}{|c|}{$\begin{array}{l}\text { Gabah Isi } \\
\text { (g) }\end{array}$} & \multicolumn{2}{|c|}{$\begin{array}{c}\text { Gabah } \\
\text { Hampa (g) }\end{array}$} & \multicolumn{2}{|c|}{$\begin{array}{c}\text { Hasil } \\
\text { (ton/ha) }\end{array}$} \\
\hline & & PHSL & FFP & PHSL & FFP & PHSL & FFP & PHSL & FFP \\
\hline 1. & Parihadi Pariyanto & 23,4 & 22,4 & 83 & 109 & 9 & 22 & 5,17 & 4,64 \\
\hline 2. & Suyamto & 22,7 & 22,8 & 103 & 119 & 50 & 44 & 3,82 & 4,27 \\
\hline 3. & Gatot & 22,0 & 22,8 & 108 & 99 & 25 & 18 & 5,32 & 4,49 \\
\hline 4. & Tarmo Santoyo & 22,5 & 21,9 & 83 & 110 & 14 & 23 & 4,81 & 3,99 \\
\hline 5. & Dwijo Suwito & 24,8 & 24,0 & 128 & 152 & 54 & 49 & 6,75 & 5,75 \\
\hline 6. & Jarkasi & 24,1 & 23,2 & 94 & 106 & 20 & 26 & 5,02 & 4,45 \\
\hline 7. & Tasmin & 22,4 & 21,2 & 105 & 105 & 20 & 19 & 4,95 & 4,59 \\
\hline 8. & Cono & 23,9 & 23,2 & 120 & 118 & 53 & 71 & 6,02 & 6,71 \\
\hline 9. & Rudiman & 22,8 & 22,7 & 94 & 118 & 14 & 29 & 4,75 & 4,32 \\
\hline 10. & Sutardi & 23,1 & 23,4 & 121 & 107 & 42 & 56 & 6,24 & 5,78 \\
\hline 11. & Atmo Waluyo & 24,3 & 23,2 & 141 & 139 & 25 & 36 & 5,57 & 5,30 \\
\hline 12. & Wito Daliyo & 22,0 & 22,2 & 82 & 103 & 23 & 22 & 3,75 & 3,63 \\
\hline 13. & Darmo & 24,6 & 25,6 & 115 & 139 & 70 & 111 & 7,25 & 6,43 \\
\hline 14. & Pardi & 23,4 & 23,4 & 89 & 85 & 41 & 39 & 5,64 & 5,68 \\
\hline 15. & Amir & 22,5 & 23,3 & 122 & 103 & 44 & 47 & 3,94 & 3,99 \\
\hline 16. & Maryono & 21,2 & 21,7 & 91 & 82 & 14 & 13 & 3,25 & 3,60 \\
\hline 17. & Saryono & 20,7 & 21,7 & 83 & 98 & 11 & 18 & 4,72 & 5,16 \\
\hline 18. & Harno & 23,5 & 21,6 & 69 & 101 & 25 & 39 & 4,19 & 4,08 \\
\hline \multirow[t]{5}{*}{19.} & Panut & 25,5 & 24,8 & 115 & 119 & 19 & 17 & 5,72 & 5,74 \\
\hline & Rata-rata & 23,1 & 22,9 & 102 & 111 & 30 & 37 & 5,10 & 4,87 \\
\hline & Standar Deviasi & 1,24 & 1,11 & 19,2 & 17,6 & 17,6 & 23,7 & 1,05 & 0,93 \\
\hline & Significantly Value & \multicolumn{2}{|c|}{0,593} & \multicolumn{2}{|c|}{0,393} & \multicolumn{2}{|c|}{0,638} & \multicolumn{2}{|c|}{0,892} \\
\hline & Thitung / T-tabel & \multicolumn{2}{|c|}{$0,59 / 1,69$} & \multicolumn{2}{|c|}{$-1,46 / 1,69$} & \multicolumn{2}{|c|}{$-0,98 / 1,69$} & \multicolumn{2}{|c|}{$0,70 / 1,69$} \\
\hline
\end{tabular}

Sumber: Data primer diolah, 2013

\section{Desa Dukuh}

Apabila dibandingkan dengan keragaan pertumbuhan tanaman pada perlakuan pemupukan seperti kebiasaan petani, pertumbuhan tanaman padi pada perlakuan pemupukan berdasarkan PHSL online di Desa Dukuh terlihat tidak berbeda nyata dalam pencapaian tinggi tanaman dan jumlah anakan. Rata-rata tinggi tanaman yang dicapai untuk pemupukan PHSL sekitar 74,0 cm dan pemupukan petani sekitar 
$73,0 \mathrm{~cm}$. Sementara untuk pencapaian jumlah anakan produktif pada petak perlakuan pemupukan PHSL sedikit lebih rendah dari pemupukan petani yaitu sekitar 24 tanaman untuk perlakuan PHSL dan 25 tanaman untuk perlakuan petani.

Rata-rata pencapaian tinggi tanaman dan jumlah anakan aktif disajikan pada Tabel 6.

Tabel 6. Rata-Rata Pencapaian Tinggi Tanaman dan Jumlah Anakan Produktif Pada Pengkajian Evaluasi Lapang PHSL Online di Desa Dukuh, Kec. Banyudono, Kab. Boyolali pada tahun 2013

\begin{tabular}{|c|c|c|c|c|c|}
\hline \multirow{2}{*}{ No. } & \multirow{2}{*}{ Nama } & \multicolumn{2}{|c|}{ Tinggi Tanaman (cm) } & \multicolumn{2}{|c|}{ Jumlah Anakan } \\
\hline & & PHSL & FFP & PHSL & FFP \\
\hline 1. & Sri Mulyani & 69,8 & 68,6 & 29 & 23 \\
\hline 2. & Mulyono & 77,0 & 82,6 & 20 & 22 \\
\hline 3. & Gito S Ngadiman & 73,6 & 68,2 & 22 & 22 \\
\hline 4. & Fajar & 77,4 & 63,4 & 20 & 20 \\
\hline 5. & Sutrimo & 62,0 & 73,2 & 21 & 26 \\
\hline 6. & Jumadi & 66,8 & 56,8 & 25 & 22 \\
\hline 7. & Sahir & 67,0 & 73,2 & 28 & 36 \\
\hline 8. & Joko Subroto & 76,4 & 77,6 & 18 & 22 \\
\hline 9. & Widono & 64,0 & 65,8 & 21 & 19 \\
\hline 10. & Jumino (Yayuk P) & 76,6 & 64,4 & 26 & 24 \\
\hline 11. & Widodo & 80,4 & 90,0 & 21 & 20 \\
\hline 12. & Budiyono & 78,8 & 78,0 & 32 & 33 \\
\hline 13. & Tri Joko & 87,2 & 66,4 & 24 & 21 \\
\hline 14. & Slameto & 75,6 & 74,2 & 23 & 31 \\
\hline 15. & Suherjan & 69,8 & 72,2 & 22 & 28 \\
\hline 16. & Slamet Miharjo & 74,0 & 75,4 & 24 & 25 \\
\hline 17. & Supami & 77,2 & 81,8 & 25 & 24 \\
\hline \multirow[t]{5}{*}{18.} & Suyamto & 82,0 & 82,0 & 23 & 28 \\
\hline & Rata-rata & 74,20 & 72,99 & 23,56 & 24,78 \\
\hline & Standar Deviasi & 6,452 & 8,261 & 3,535 & 4,747 \\
\hline & Significantly Value & \multicolumn{2}{|c|}{0,388} & \multicolumn{2}{|c|}{0,237} \\
\hline & Thitung / T-tabel & \multicolumn{2}{|c|}{$0,49 / 1,69$} & \multicolumn{2}{|c|}{$-0,88 / 1,69$} \\
\hline
\end{tabular}

Sumber: Data primer diolah, 2013

Berdasarkan hasil pengamatan terhadap rata-rata panjang malai, jumlah gabah isi dan gabah hampa, keragaan komponen hasil di Desa Dukuh untuk perlakuan PHSL dan eksisting petani tidak menunjukkan adanya perbedaan yang nyata. Rata-rata panjang malai pada petak PHSL sedikit lebih pendek dari petani yaitu masingmasing sekitar 21,8 cm dan 23,4 cm. Sementara rata-rata pencapaian jumlah gabah isi dan gabah hampa untuk perlakuan PHSL sedikit lebih banyak dari petani yaitu masing-masing sekitar 115/31 dan 110/46. Data pencapaian panjang malai dan jumlah gabah isi hampa di Desa Dukuh disajikan pada Tabel 7.

Tabel 7. Data Panjang Malai, Gabah Isi dan Gabah Hampa, dan Hasil Gabah Pada Evaluasi Lapang PHSL Online di Desa Dukuh, Kec. Banyudono, Kab. Boyolali pada tahun 2013

\begin{tabular}{|c|c|c|c|c|c|c|c|c|c|}
\hline \multirow{2}{*}{ No. } & \multirow{2}{*}{ Nama } & \multicolumn{2}{|c|}{$\begin{array}{l}\text { Panjang } \\
\text { Malai }(\mathrm{cm})\end{array}$} & \multicolumn{2}{|c|}{$\begin{array}{l}\text { Gabah Isi } \\
\text { (g) }\end{array}$} & \multicolumn{2}{|c|}{$\begin{array}{c}\text { Gabah } \\
\text { Hampa (g) }\end{array}$} & \multicolumn{2}{|c|}{$\begin{array}{c}\text { Hasil } \\
\text { (ton/ha) }\end{array}$} \\
\hline & & PHSL & FFP & PHSL & FFP & PHSL & FFP & PHSL & FFP \\
\hline 1. & Sri Mulyani & 22,4 & 24,2 & 109 & 115 & 25 & 40 & 6,94 & 7,14 \\
\hline 2. & Mulyono & 20,8 & 22,5 & 128 & 121 & 16 & 33 & 5,14 & 5,47 \\
\hline 3. & Gito S Ngadiman & 19,4 & 21,7 & 108 & 108 & 31 & 55 & 5,30 & 4,94 \\
\hline 4. & Fajar & 22,6 & 25,0 & 128 & 126 & 36 & 86 & 8,53 & 9,49 \\
\hline 5. & Sutrimo & 20,8 & 23,6 & 132 & 116 & 45 & 46 & 8,65 & 8,00 \\
\hline 6. & Sahir & 21,0 & 23,5 & 95 & 106 & 65 & 79 & 10 & 9,38 \\
\hline 7. & Joko Subroto & 21,5 & 24,0 & 104 & 109 & 31 & 53 & 7,19 & 7,65 \\
\hline 8. & Widono & 21,7 & 23,1 & 111 & 96 & 17 & 36 & 7,99 & 9,06 \\
\hline 9. & Supomo & 22,1 & 24,4 & 139 & 117 & 11 & 14 & 8,44 & 8,27 \\
\hline 10. & Jumino (Yayuk P) & 20,9 & 22,4 & 113 & 102 & 21 & 23 & 7,29 & 5,95 \\
\hline 11. & Widodo & 24,0 & 24,6 & 119 & 141 & 6 & 17 & 6,91 & 7,00 \\
\hline 12. & Budiyono & 24,1 & 23,5 & 113 & 100 & 49 & 44 & 8,18 & 8,18 \\
\hline 13. & Tri Joko & 20,9 & 24,7 & 114 & 111 & 14 & 24 & 7,00 & 7,52 \\
\hline 14. & Slameto & 22,3 & 23,0 & 109 & 112 & 64 & 84 & 9,42 & 9,69 \\
\hline 15. & Suherjan & 21,1 & 22,5 & 100 & 77 & 17 & 41 & 4,97 & 5,33 \\
\hline 16. & Slamet Miharjo & 22,8 & 22,1 & 90 & 92 & 11 & 8 & 6,97 & 6,70 \\
\hline 17. & Supami & 21,4 & 24,3 & 136 & 118 & 29 & 86 & 7,97 & 8,01 \\
\hline \multirow[t]{5}{*}{18.} & Suyamto & 22,1 & 22,9 & 117 & 108 & 65 & 51 & 7,85 & 7,91 \\
\hline & Rata-rata & 21,8 & 23,4 & 115 & 110 & 31 & 46 & 7,49 & 7,54 \\
\hline & Standar Deviasi & 1,17 & 0,98 & 13,7 & 13,9 & 19,4 & 24,9 & 1,38 & 1,44 \\
\hline & Significantly Value & \multicolumn{2}{|c|}{0,637} & \multicolumn{2}{|c|}{0,810} & \multicolumn{2}{|c|}{0,371} & \multicolumn{2}{|c|}{0,817} \\
\hline & Thitung / T-tabel & \multicolumn{2}{|c|}{$-4,65 / 1,69$} & \multicolumn{2}{|c|}{$1,09 / 1,69$} & \multicolumn{2}{|c|}{$-1,99 / 1,69$} & \multicolumn{2}{|c|}{$-0,11 / 1,69$} \\
\hline
\end{tabular}

Sumber: Data primer diolah, 2013

Hasil evaluasi lapang pemupukan berdasarkan PHSL online di Desa Dukuh (Tabel 7) secara umum menunjukkan bahwa dari rata-rata hasil secara keseluruhan (dari 18 petani) perlakuan pemupukan PHSL mencapai hasil sedikit lebih 
rendah dibandingkan pemupukan petani, yaitu sekitar 5,2\% (66,7\% petani). Sementara sisanya sekitar 33,3\% petani hasil yang dicapai pada perlakuan PHSL lebih tinggi sekitar 6,7\% dari pemupukan eksisting.

Berdasarkan hasil uji T pada data tinggi tanaman, jumlah anakan, panjang malai, jumlah gabah isi dan hampa serta hasil gabah per hektar di Desa Dukuh terlihat adanya nilai perbedaan (significantly value) $>5 \%$ yang berarti data kedua perlakuan (PHSL dan FFP) relatif homogen. Dilihat dari nilai T-hitung yang lebih kecil dari T-tabel menunjukkan kedua perlakuan memiliki rata-rata hasil pada setiap parameter yang relatif sama. Sementara nilai negatif pada T-hitung menunjukkan adanya indikasi bahwa perlakuan PHSL memiliki nilai yang relatif lebih rendah dibandingkan FFP.

\section{Analisis Keuntungan Sederhana}

Hasil pengkajian evaluasi lapang terhadap ketepatan rekomendasi pemupukan berdasarkan program PHSL online juga dilakukan penilaian perubahan keuntungan finansial secara sederhana.

Tabel 7. Analisis Keuntungan Sederhana Terbatas Pada Perbedaan Input Penggunaan Pupuk dan Hasil Pada Pengkajian Evaluasi Lapang PHSL Online di Boyolali pada tahun 2013

\begin{tabular}{|c|c|c|c|c|c|}
\hline \multirow{2}{*}{ No. } & \multirow{2}{*}{ Desa } & \multirow{2}{*}{ Uraian } & \multicolumn{2}{|c|}{ Nilai (Rp) } & \multirow{2}{*}{$\begin{array}{l}\text { Selisih } \\
\text { PHSL vs } \\
\text { FFP (\%) }\end{array}$} \\
\hline & & & PHSL & FFP & \\
\hline \multirow[t]{4}{*}{1.} & Trayu & Total biaya pupuk & 983.182 & 1.647 .261 & $-40,31$ \\
\hline & & Hasil (kg/ha) GKG & 5.099 & 4.874 & 4,62 \\
\hline & & Total penerimaan & 22.945 .263 & 21.931 .579 & 4,62 \\
\hline & & Keuntungan (input pupuk) & 21.962 .081 & 0.284 .318 & 8,27 \\
\hline \multirow[t]{4}{*}{2.} & Dukuh & Total biaya pupuk & 922.867 & 1.338 .900 & $-31,07$ \\
\hline & & Hasil (kg/ha) GKG & 6.739 & 6.784 & $-0,67$ \\
\hline & & Total penerimaan & 33.693 .156 & 33.918 .841 & $-0,67$ \\
\hline & & Keuntungan (input pupuk) & 32.770 .289 & 32.579 .941 & 0,58 \\
\hline
\end{tabular}

Analisis keuntungan pada hasil evaluasi ini hanya didasarkan pada beberapa faktor peubah utama yaitu perbedaan biaya penggunaan pupuk dan perubahan produktivitas dengan mengasumsikan faktor-faktor input produksi yang lainnya sama. Hasil analisis keuntungan sederhana disajikan pada Tabel 8.

Berdasarkan Tabel 8 di atas terlihat bahwa rekomendasi pemupukan berdasarkan PHSL di Desa Trayu terdapat selisih biaya penggunaan pupuk, dimana rekomendasi PHSL lebih rendah 40,31\% dibandingkan petani. Namun demikian karena selisih produktivitas padi yang dihasilkan relatif kecil, maka selisih keuntungan terakhir yang diterima juga relatif kecil. Penerapan rekomendasi pemupukan berdasarkan PHSL memberikan selisih keuntungan sebesar 8,27\% lebih tinggi dari petani.

Hasil analisis keuntungan sederhana di Desa Dukuh menunjukkan bahwa rekomendasi pemupukan berdasarkan PHSL mempunyai selisih biaya penggunaan pupuk yang lebih rendah dari petani, yaitu sekitar 31,07\%. Sementara pencapaian produktivitas padi antara pemupukan PHSL dengan petani relatif sama. Oleh karena itu, perolehan keuntungan bersih dari penggunaan input pupuk pada penerapan rekomendasi pemupukan berdasarkan PHSL hanya sedikit lebih tinggi dari petani yaitu sekitar 0,58\%. Dengan demikian rekomendasi pemupukan berdasarkan PHSL online masih lebih menguntungkan dibandingkan kebiasaan petani setempat.

\section{SIMPULAN}

Berdasarkan hasil dan pembahasan tersebut di atas, maka dapat ditarik kesimpulan sebagai berikut:

1. Rekomendasi pemupukan padi sawah berdasarkan PHSL online secara umum lebih ren- 
dah dibandingkan rata-rata kebiasaan petani, namun tidak berpengaruh terhadap pertumbuhan tanaman dan komponen produksi padi di Desa Trayu dan Dukuh Kecamatan Banyudono Boyolali.

2. Penerapan rekomendasi pemupukan berdasarkan program PHSL online mampu menghasilkan produksi padi yang sebanding (sedikit lebih tinggi) dari kebiasaan pemupukan petani, dengan dosis pemupukan yang relatif lebih rendah.

3. Secara umum rata-rata tingkat efisiensi agronomi padi pada rekomendasi PHSL online adalah pupuk $\mathrm{N}$ sebesar $0,7 \mathrm{~kg} / \mathrm{kg}, \mathrm{P}$ dan $\mathrm{K}$ masing-masing $2,3 \mathrm{~kg} / \mathrm{kg}$.

4. Secara proporsional di masing-masing lokasi pengkajian, penerapan rekomendasi pemupukan berdasarkan PHSL di Desa Trayu sekitar $63,2 \%$ petani lebih baik (5,31 ton/ha) dari eksisting (4,79 ton/ha), sedangkan di Desa Dukuh hanya sekitar 33,3\% petani lebih baik (7,84 ton/ha) dari eksisting (7,35 ton/ha).

5. Berdasarkan analisis keuntungan sederhana, rekomendasi pemupukan berdasarkan PHSL online memberikan perbedaan keuntungan yang positif dari eksisting sekitar 8,27\% di Desa Trayu dan 0,58\% di Desa Dukuh.

6. Rekomendasi pemupukan berdasarkan PHSL online di Kecamatan Banyudono Boyolali untuk unsur $\mathrm{N} 4,1 \%$ lebih rendah, $\mathrm{P}_{2} \mathrm{O}_{5} 27,2 \%$ lebih tinggi dan $\mathrm{K}_{2} \mathrm{O}$ 15,6\% lebih tinggi dari Permentan.

\section{SARAN DAN IMPLIKASI KEBIJAKAN}

1. Rekomendasi PHSL online lebih efisien dalam penggunaan pupuk dibandingkan petani, oleh karena itu pendekatan ini sebaiknya digunakan sebagai strategi untuk mengantisipasi keterbatasan dan kelangkaan alokasi pupuk bersubsidi. Sebagai langkah awal, model penentuan rekomendasi pupuk berdasarkan PHSL online ini perlu segera dipraktekkan dan didiseminasikan terutama di daerah-daerah yang sering dihadapkan dengan masalah kekurangan pupuk.

2. Keakuratan dan kevalidan rekomendasi pemupukan berdasarkan PHSL masih perlu dievaluasi dan divalidasi dalam skala luas, serta dikomparasikan dengan metode lain seperti uji tanah dan Permentan 40/2007.

3. Program PHSL sebaiknya perlu mempertimbangkan variasi pola tanam terutama tanaman padi yang bergilir dengan palawija atau bera4.

4. Program baru mengasumsikan penggunaan varietas yang sama pada beberapa musim yang telah berjalan sehingga perlu pemikiran kombinasi varietas mengingat cepatnya perkembangan varietas dan perubahan (anomali) iklim.

\section{UCAPAN TERIMA KASIH}

Terima kasih dan penghargaan yang setinggitingginya kami sampaikan kepada IRRI (c.q. Bpk. Sunendar Kartaatmadja selaku konsultan pendamping) atas dukungan pembiayaan dan pendampingan kegiatan ini, Bpk. Jumadi, Bpk. Sugimin, Ibu Kenari Jenar dan Ibu Anita atas bantuannya dalam mengawal dan memberikan penyuluhan kepada petani kooperator dalam pelaksanaan kegiatan evaluasi lapang PHSL online ini.

\section{DAFTAR PUSTAKA}

AGRINA, 2011. Pemupukan akurat dengan PHSL. Tabloid Agribisnis Dwi Mingguan - Inspirasi Agribisnis Indonesia, 15 Agustus 2011.

Badan Litbang Pertanian, 2007. Rekomendasi Pemupukan N, P dan K Pada Padi Sawah Spesifik Lokasi (Penyempurnaan). Peraturan Menteri Pertanian No. 40/Permentan/ OT.140/4/2007 tanggal 11 April 2007. Departemen Pertanian. 
Buresh, R.J., D. Setyorini, S. Abdulrachman, F. Agus, C. Witt, I. Las, S. Hardjosuwirjo. Improving nutrient management for irrigated rice with particular consideration to Indonesia. Rice industry, culture and environment: Book 1. Proceedings of the International Rice Conference, 12-14 September 2005, Bali, Indonesia. Indonesian Center for Rice Research (ICRR), Indonesian Center for Food Crops Research and Development (ICFORD), and Indonesian Agency for Agricultural Research and Development (IAARD).

Buresh. R., 2008. Balancing Fertilizer Use and Profit. Rice Today January-March 2008. International Rice Research Institute.

IPNI, 2004. Profit Analysis Based on Fertilizer Application. International Plant Nutrition Institute. ESEAP Program, Singapore.

IRRI, 2011. Nutrient Management for Rice. http://webapps.irri.org/ $\mathrm{nm} / \mathrm{id}$

Kementan, 2011. Pemupukan Hara Spesifik Lokasi (PHSL) Padi Sawah. Nutrient Manager for Rice (NM Rice) Indonesia Versi 1.11. Kerjasama Kementerian Pertanian Republik Indonesia Dengan International Rice Research Institute (IRRI).

Puslitbangtan, 2006. Pemupukan Padi Sawah. Kerjasama Puslitbangtan - BBSDLP - BBP2TP - BB Padi - IRRI, 2006

Puslitbangtan, 2013. Adopsi Teknologi PHSL di Indonesia Mendukung P2BN. Pusat Penelitan dan Pengembangan Tanaman Pangan. 18 Februari 2013.

Samijan, 2008. Pemupukan berimbang dalam rangka mendukung peningkatan produktivitas padi dan palawija. Makalah Pertemuan Workshop Perbaikan Kesuburan Lahan. Direktorat Pengelolaan Lahan, 2008. 